\title{
Analysis on the Evolution and Innovation Essence of Product Life Cycle Oriented Marketing Theory
}

\author{
Yan Wang * \\ Shandong Vocational and Technical University of International Studies, Rizhao, Shandong \\ 276826, China \\ * profmu@cumt.edu.cn
}

\begin{abstract}
Every development of marketing theory is based on the gradual improvement of the previous theory and the summary of the practical test results. This paves the way for the emergence of renewal theory. According to the order of time, this paper takes $4 \mathrm{Ps} \rightarrow \mathrm{NPs} \rightarrow 4 \mathrm{Cs} \rightarrow 4 \mathrm{Rs}$ as the main line of discussion, and deeply expounds the principles and innovation development history of various marketing theories. And to carry on the substantive analysis research to them. Based on the product life cycle-oriented marketing theory evolution theory, this paper analyzes the essence and function of marketing from the current fierce business war. Then, starting from the four stages of product life cycle theory, this paper puts forward the marketing strategy of indifference applied in different stages of product life cycle and the problems that should be paid attention to in the process of enterprise marketing activities. The experimental data show that the proposed method can well describe the evolution process of marketing theory. This provides a certain reference value for the analysis of the essence of marketing innovation.
\end{abstract}

Keywords: Marketing; Product Life Cycle; Theory Evolution; Innovation Essence.

\section{Introduction}

The development of network economy, the progress of digital technology, the further diversification of network use and the more and more frequent use of Internet promote the emergence and development of aggregation marketing concept [1]. What the Internet has launched is not only an information revolution, more importantly, the Internet has gradually penetrated into all aspects of people's lives, and is changing people's way of thinking and behavior [2-3]. Of course, including the huge impact on consumer values and purchasing behavior. As a result, many visionary business and academic circles began to predict that with the increasingly significant impact of the Internet on consumers, a new type of consumer groups - "digital consumers" will emerge, and thus the "Internet market" which is different from the traditional market will emerge.

Therefore, in the late 1990s, many entrepreneurs and observers began to focus on the growth of "digital consumers" and the emergence of "Internet market" [4-5]. Entrepreneurs and marketing personnel in the enterprise began to widely discuss and apply the network marketing mode completely separated from the traditional marketing. However, we soon found that pure digital consumers are an unreal group to a large extent [6]. Today's consumers are actually the aggregation of traditional consumers and digital consumers. Their consumption behavior uses both traditional channels and digital channels provided by the network to meet their own needs and desires. As shown in Figure 1: Today's consumer behavior "combines traditional and digital, rational and emotional, virtual and real factors [7-8]. This kind of consumer is not one of the two, but a mixture of them."

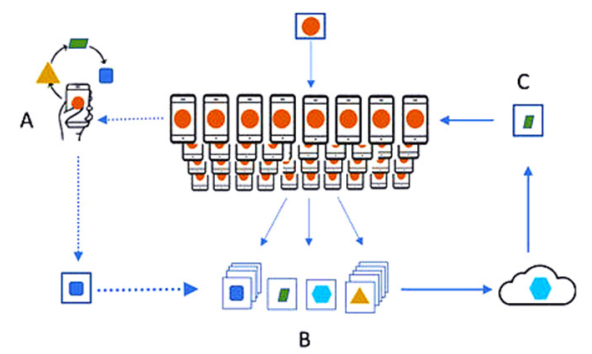

Figure 1. Aggregated consumers 


\section{The Theoretical Basis of Aggregation Marketing and its Product Strategy Research}

\subsection{Consumer Behavior Theory}

Consumer behavior theory studies consumer's response to products, services and marketing activities. Consumer behavior is very important for marketing, because modern marketing is based on consumer centered, and consumer needs and desires are the starting point of marketing activities [9-10]. In the fierce market competition, only enterprises that really understand consumers can develop better products and services, promote their products and services to consumers more effectively, and design effective market strategies to cultivate sustainable competitive advantages for their products and services.

In order to understand the value and shopping behavior of consumers and why they make a choice rather than other choices, consumer behavior theory makes an in-depth and extensive research on people's reactions. These reactions of consumers are the basis for enterprises to carry out marketing, because only after enterprises understand the reactions of consumers to their marketing strategies, can enterprises formulate the products, services and marketing strategies that can move consumers and meet their needs according to the reactions of consumers. At the same time, only when enterprises deeply understand these reactions of consumers can they establish, maintain and strengthen the relationship with customers, so that the interests of both customers and enterprises can be satisfied and integrated (as shown in Figure 2).

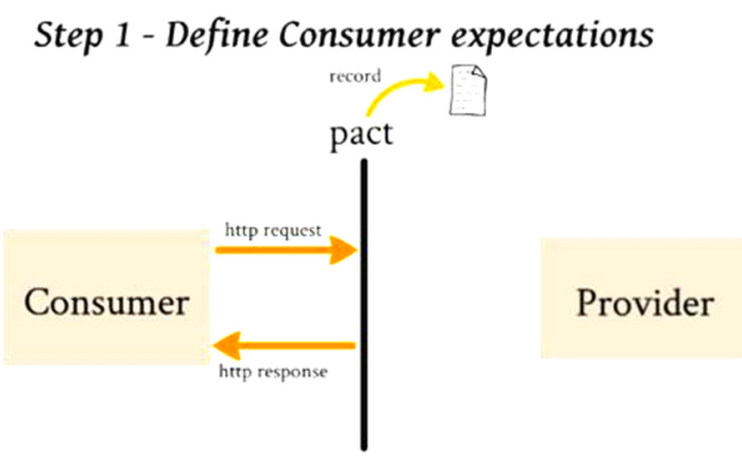

Figure 2. Consumer response

\subsection{Marketing Engineering Theory}

Marketing engineering theory is a systematic process of applying marketing data and knowledge to practice through planning, design, decision support and marketing management support system. Specifically, marketing engineering theory is to integrate marketing concepts, subjective or objective marketing data, marketing problems in the market, marketing decision-making model, marketing management system and information system to help marketing personnel to realize the process, quantity and science of decision-making, and improve the correctness of decision-making and the profitability of marketing investment.

In the past, people often argued about whether marketing was an art or a science. Some people think that marketing is art, while others think that marketing is science. Marketing engineering theory regards marketing as an engineering, combining science and art, and its purpose is to solve specific marketing problems. The core method of marketing engineering theory is to use computer decisionmaking model to transform the subjective and objective marketing data from external marketing environment into market insight, marketing decision-making and decision-making execution.

\subsection{Transaction Marketing Theory}

The transaction marketing theory takes the transaction as the core, and takes the marketing mix management theory as the main. The core of the theory of marketing mix management is how to 
attract the consumers in the target market to buy the products and services of the enterprise through the internal control of 4Ps. Its essence is to achieve the transaction between the enterprise and the customers.

The basic point of 4Ps is that although there are many contents of marketing activities, they can be summarized into four categories: product, price, place and promotion. These four factors are closely related and interact with each other. Marketing personnel should be unified, coordinated and managed to form a harmonious whole to attract consumers in the target market to buy the products and services of the enterprise and facilitate the transaction between the enterprise and customers. 4Ps can also be expressed as follows: if the company produces the right products, sets the right price, uses the right distribution channels, and complements with the right promotion activities, then the company will succeed (as shown in Figure 3).

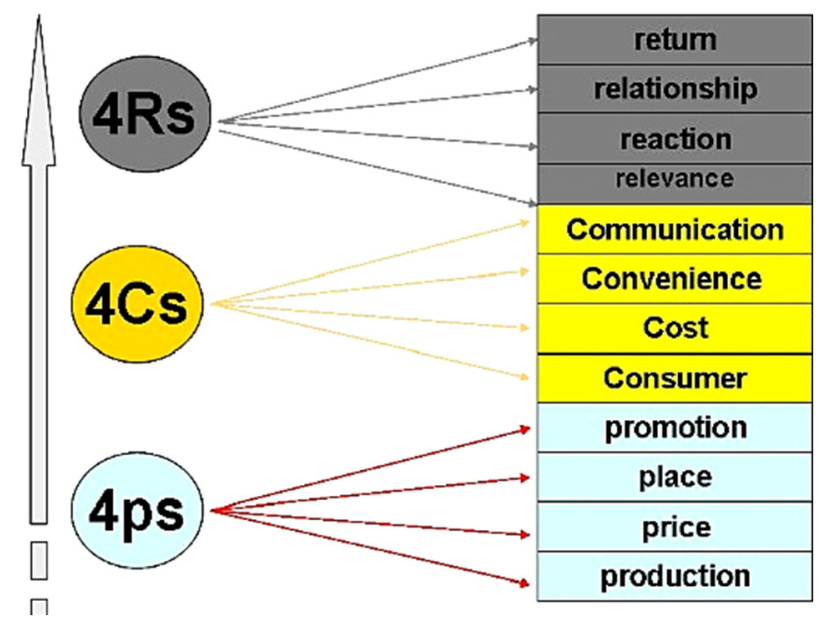

Figure 3. 4Ps theory

\section{An Analysis of the Causes of Aggregation Marketing}

\subsection{The Boom of Network Economy and the Breakup of Bubble}

In the 1990s, with the gradual popularization of computer applications and the Internet, all sectors of society believe that the network economy will replace the traditional economy and become the most important driving force of the national economy. At that time, people were generally optimistic that the network economy could bring high efficiency, provide a low transaction cost, and bring about a complete change in the economic system. At that time, the U.S. Nasdaq stock price index all the way up. The proportion of new economy in developed countries is higher and higher, even more than that of traditional industries; there are many Internet upstarts, such as Yahoo, Sohu, Sina, etc., and many relatively successful online stores, such as Amazon, 8848, Dangdang bookstore, etc., and the new economy of the United States has maintained rapid growth for more than 100 consecutive months.

In March 2000, Ms. Cohen, chief strategic analyst of Goldman Sachs securities, thought that the rise of technology stocks represented by Internet stocks was too strong, and advised customers to reduce their stock holdings. NASDAQ (NASDAQ) fell to the ground, and since then the bubble of the network economy has broken down. From March 10 to 23, the NASDAQ index plummeted 37\%. Although it recovered half of its decline by mid July, its market value has lost $40 \%$.

It is the breakup of the bubble of the network economy that makes people begin to rationally treat the impact of high technology and the Internet on mankind. As Wender and others believe, many early dot com companies made fatal mistakes. They are so addicted to hot technologies, business models and massive capital investments that they forget the consumers who are likely to dominate their business. Many Internet companies take it for granted that consumers can get huge benefits by making the shopping process more efficient through the Internet. However, these enterprises obviously did not expect that many consumers actually like the shopping experience. In the boom of 
Internet economy, the marketing staff of Internet companies often do not realize the reasons why people buy things, and how these emotions affect the way they buy. The boom of the network economy and the breakdown of the bubble provide the necessary background for the emergence of the convergence marketing.

\subsection{Increasingly Fierce Business Competition}

The increasingly fierce business competition is the business driving factor of aggregation marketing. With the increasingly fierce market competition, consumers have more and more initiative to choose products, and with the gradual opening of China's entry into the WTO, how many industries and enterprises that have been protected by the state can survive in the cruel market competition is the main concern of many enterprises.

In the 21 st century, when the market competition is so fierce, marketing is obviously the most important part of enterprises, because we all know that "the winners in the market are the companies that can best adapt to the current environment - they provide goods to the people who really need to buy." However, in such a fierce business competition, the company's marketing is not only through a few advertisements, make a few promotions on the line. What enterprises and companies need to do now is to clearly realize that in the digital age, the value and purchasing behavior of consumers have changed. Of course, they can't think that consumers have completely changed as technology advocates do, and the past marketing strategies and methods are useless. Enterprises should understand that today's consumers are mixed consumers. Therefore, if they want to take the lead in the fierce market competition, enterprises need to seriously think about the current consumers through the aggregation marketing concept, and create a new set of marketing strategies, so as to win in this consumer centered market. The increasingly fierce commercial competition is the commercial motivation for the emergence and application of aggregation marketing concept.

\section{Research on the Definition and Marketing Strategy of Aggregate Marketing}

\subsection{Definition of Aggregate Marketing}

According to the concepts of marketing and aggregation, this paper defines aggregation marketing as follows

In the digital era, based on the aggregation of new technologies and human's persistent behavior habits on the part of consumers, the enterprises have adopted different types of new technologies (including TV, computer, Internet, mobile phone, PDA, personal digital processing assistant, etc.). Multi channel (online and offline, website and non website, digital and traditional) or combination of multi means (transaction marketing and relationship marketing) is a social and management process to establish, maintain and strengthen the relationship with customers and other partners, so as to meet and integrate the interests of all parties.

The definition of aggregation marketing shows that aggregation marketing is firstly a social and management process, and its purpose is to satisfy the interests of enterprises, customers and other partners in the process. In order to achieve this goal, the means adopted are the combination of different types of new technologies (including TV, computer, Internet, mobile phone, PDA personal digital processing assistant, etc.), multi-channel (online and offline, website and non website, digital and traditional) or multi-channel (transaction marketing and relationship marketing). Establish, maintain and strengthen the relationship among partners in the process. Then the premise of aggregation marketing is the aggregation of new technology and human's lasting behavior habits in the digital age.

\subsection{Marketing Strategy of Aggregation Marketing}

1) Traditional transaction marketing strategy

In the traditional transaction marketing theory, when it comes to marketing strategy, people will naturally think of 4Ps combination, that is, product, price, promotion and channel or place. The basic 
points are: Although there are many contents of marketing activities, they can be summarized into four categories: product, price, promotion and channel or channel; these four factors are closely related and interact with each other, so their strategies should be unified to form a coordinated overall marketing strategy.

4Ps marketing mix theory essentially reflects the effect of environmental variables on consumer behavior in consumer behavior theory. Although establishing, maintaining and strengthening the relationship with customers is the main purpose of aggregation marketing strategy, the traditional 4Ps marketing mix theory can also be used to attract new customers, and the relationship with customers can be established by combining the first level of relationship marketing, which is the first level of three relationship marketing levels to create customer value. Moreover, because of its simplicity and ease of operation, as well as the special emphasis on operability of marketing strategy, the traditional transaction marketing strategy still constructs the main framework of aggregate marketing strategy.

2) Marketing strategy of aggregation marketing

Aggregation marketing comes into being in a new era, in which consumers gradually participate in enterprise decision-making, and enterprises and customers communicate with each other. This era is a more customized era, all processes are consumer centered, and this era is an era of unlimited emphasis on mutual communication. Consumers are gradually in a dominant position in this era. Consumers can use more new technologies and the Internet to help them make the right purchase decisions, and they will be more active in interacting with enterprises. In addition, because the traditional transaction marketing theory and relationship marketing theory are the theoretical guidance of aggregation marketing idea, the traditional 4Ps marketing strategy and the 4Cs marketing strategy in relationship marketing have a guiding role for aggregation marketing strategy. And because the traditional 4Ps and 4Cs marketing strategy in relationship marketing have their own advantages and disadvantages, so the marketing strategy of aggregate marketing should take the combination of 4Ps and 4Cs. Among them, any P in 4Ps theory is still very important today, but every $P$ has changed because of the role of new technology and the Internet. To sum up, the marketing strategy of aggregation marketing should combine the 4Ps of traditional marketing, 4Cs of 1990s, and the changes brought about by new technology and Internet to form a marketing strategy of aggregation marketing based on the four aspects of product strategy aggregation, price strategy aggregation, channel strategy aggregation and communication strategy aggregation.

\section{Product Strategy of Aggregate Marketing}

In the traditional transaction marketing theory, the solution to the problem is the product or core service provided by the enterprise in the form of entity. In the traditional transaction marketing theory, products need to be considered from three levels (as shown in Figure 4).

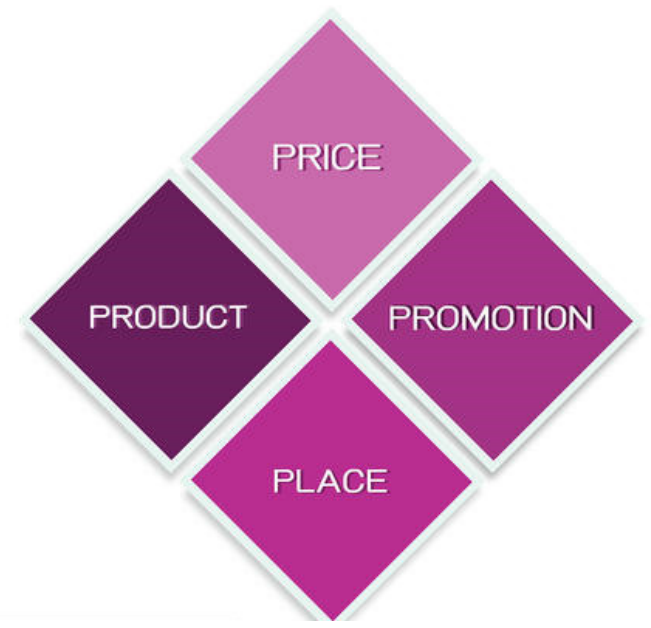

Figure 4. Three levels of products in transaction marketing theory 
The most basic level is core product, which mainly raises the question of what consumers need to buy. The core product layer is in the most central position, which includes the core interests or basic services consumers seek to buy products. In the traditional transaction marketing, the core product level is the most basic level considered by the marketing personnel in product design, which is directly related to the needs and desires of consumers. The second level of products is the level of tangible products. In this level, the marketing personnel transform the core products into physical products composed of function, style, quality level, brand name and packaging. The last level of product is the auxiliary product level. In this level, marketing personnel mainly provide some additional services or benefits to consumers according to the core products and stylish products.

In the marketing mix decision of traditional transaction marketing theory, product strategy is the most basic and important one. Product is not only the core of traditional marketing strategy, but also the key of the whole enterprise strategy. Product positioning also has a great influence on marketing strategy and other marketing variables.

In the theory of relationship marketing, the concept of product is more inclined to the term "solution to the problem". According to the theory of communication, interaction, dialogue and value process in relationship marketing, the solution to the problem (or product) is the relationship itself and the process of creating value and satisfying customers through the relationship. Therefore, in the theory of relationship marketing, the enterprise makes the customer become a real and active cooperator of the enterprise through the customized problem-solving solution, and establishes different degrees of cooperative relationship with the customer in the process of interaction.

According to the theory of three levels of relationship marketing to create customer value in relationship marketing, when enterprises interact with customers through customized problemsolving solutions, they can adopt the product strategy of establishing three different levels of relationship with customers in different situations.

The first level relationship strategy is to attract customers to establish a long-term transaction relationship with the enterprise through price and other means of financial value transfer. For example, enterprises give financial rewards to customers who purchase frequently or according to a stable quantity, so as to establish the relationship between customers and enterprises.

Secondary relationship strategy is to increase the financial benefits of customers, at the same time, try to understand the needs and wishes of individual customers, provide personalized and personalized products and services, so as to increase the social contact between the company and customers.

The three-level relationship strategy is to increase the structural ties between enterprises and customers while increasing the financial and social benefits for customers. The three-level relationship strategy is usually based on technology, which makes enterprises and customers depend on each other's structural changes.

\section{Conclusion}

Based on the theory of consumer behavior, this paper points out that due to the influence of the new economy and the Internet, consumers in the digital age have many different values and purchasing behaviors from traditional consumers. However, because consumers in the digital age also have basic human values and behavior attributes, they have some unchanged values and purchasing behaviors from traditional consumers. The change and invariance of consumer values and purchase behavior in the digital era lead to the formation of comprehensive consumers in the digital era, and directly promote the emergence of aggregation marketing concept.

Aggregate marketing is the guiding theory for enterprises to take marketing activities for comprehensive consumers in the digital era. On the one hand, it aims at the unique value and purchase behavior of consumers in the digital era, and provides an analysis framework for enterprises to carry out marketing activities through the analysis and integration of online and offline markets, which leads to a new perspective and basis for enterprises to carry out marketing activities in the 21 st century. 
On the other hand, it integrates traditional transaction marketing theory, relationship marketing theory, Internet and high-tech means. Therefore, the marketing strategy of aggregation marketing should combine the 4Ps of traditional marketing, 4Cs of transaction marketing and the changes brought about by new technology and Internet to form the marketing strategy of aggregation marketing based on the four aspects of product strategy aggregation, price strategy aggregation, channel strategy aggregation and communication strategy aggregation.

\section{References}

[1] Deng Qian. Analysis of the Reasons for the Disconnection Between Marketing Theory and Practice. China Civil Business, 2018 (5): 46-49.

[2] Zhou Jianmin. Centennial Development and Innovation of Marketing Theory. Financial Economics Research, 2002 (01): 75-77.

[3] Wei Li Peng, Shi Hua Miao. Institutional Analysis of the Evolution of Marketing Theory. Contemporary Finance and Economics, 2001 (06): 60-62.

[4] Chang Yongsheng. Reform and Progress of Marketing Theory in the 20th Century. Southern Economics, 2000 (07): 46-48.

[5] An Xianglin, Shi Dongju, Zhao Xingyan. on the Development of Marketing Theory. China Science and Technology Information, 2007, 1: 240-240.

[6] Zhang Hongzeng, Gao Li. Origin, Development and Prospect of Marketing Theory. Enterprise Reform and Management, 2006, 5: 14-15.

[7] Li Bo, Zhao Shengli, Cui Liuxin. Application of 4rs Marketing Theory in Community Health Service. Chinese Journal of Social Medicine, 2017, 034 (005): 489-491.

[8] Yi Aidi, Zeng Lu. Research on the Relationship Between Positioning Theory and Marketing Theory. Business Era, 2010 (27): 21-22.

[9] Wei Xiaolin. the Dilemma of University Positioning from the Perspective of Marketing Theory. Higher Agricultural Education, 2006 (11): 22-25.

[10] Zhang Lu, Fei Xiangjun, Zhou Shu. Exploration of Experiential Teaching of Stp Theory in Secondary Vocational Marketing. Education Research (2630-4686), 2020, 003 (002): P.28-29. 